\title{
МЕТОДИЧЕСКИЕ ПОДХОДЫ К МОДЕЛИРОВАНИЮ ПРИ УПРАВЛЕНИИ МЕЖСЕКТОРНЫМ ПАРТНЁРСТВОМ
}

Лапцова Е.С. ФГБУН «Вологодский научный центр РАН», г. Вологда

Статья посвящена анализу наиболее распространённыхметодов моделирования при управлении межсекторным сочиальным партнёрством в рамках системного подхода. Автором приведено описание каждого из них и выбраны наиболее подходящие методы моделирования для последующих исследований изучаемого феномена.

Ключевые слова: некоммерческий сектор, бизнес, власть, общество, межсекторное партнёрство, межсекторное взаимодействие, моделирование.

В современных условиях взаимодействие власти, бизнеса и общества становится одним из действенных способов решения социальных проблем, как в развитых, так и в развивающихся странах. Применение инструментов межсекторного социального партнерства во многом является залогом успешного развития общественно-государственного управления. Темпы развития межсекторного партнерства сегодня набирают высокие обороты за счет объединения ресурсов бизнеса, государства и некоммерческих организаций.

Генезис межсекторного социального партнерства свидетельствует о том, что данный феномен появился в ответ на возникшую в конце прошлого века социальную потребность. В настоящее время он продолжает своё развитие в виде формирования механизма взаимодействия между государственным, коммерческим и некоммерческим секторами.

В то же время обзор трудов отечественных исследователей свидетельствует о том, что межсекторное социальное партнерство в России сегодня нуждается в дальнейшей институционализации.

Процесс интеграции секторов и его оформление в конкретную модель протекает с существенными затруднениями, что во многом обусловлено недостаточным опытом применения инструментов и методов межсекторного партнёрства. В связи с этим большую актуальность приобретает изучение методических подходов к моделированию МСП.

Цель данного исследования - проанализировать и оценить наиболее распространённые методические подходы к моделированию при управлении межсекторным партнёрством.

Задачи исследования:

- рассмотреть основные методические подходы к моделированию, применяемые при управлении МСП и коллективной деятельностью в целом;

- выявить достоинства и недостатки указанных методов; 
- выбрать наиболее подходящие методы моделирования при управлении межсекторным партнёрством для последующей научной работы.

Объектом данного исследования является межсекторное социальное партнёрство как сложная система, которая состоит из различных подсистем, связанных друг с другом и с внешней средой.

Сегодня моделирование получило широкое развитие в общественных науках, в том и числе и в сфере управления различными системами. Рассматривая классификацию видов моделирования систем, можно выделить следующие виды моделирования: наглядное (гипотетическое, аналоговое, макетирование), математическое (аналитическое, комбинированное, имитационное), физическое (в масштабе времени), символическое (языковое и знаковое), натурное (эксперимент, испытания и пр.) [12].

В настоящее время выделяются различные методические подходы к моделированию с точки зрения системного анализа. Систему можно рассматривать с двух позиций - как состоящую из подсистем, связанных друг с другом (структурный подход), и как систему, включающую в себя ряд свойств, функций, способствующих достижению стоящей перед ней цели (функциональный подход) [10].

Различные авторы предлагают собственные подходы к моделированию межсекторного партнёрства. Однако большинство из них рассматривают МСП сквозь призму структурного подхода.

Наиболее известная сегодня модель МСП выглядит следующим образом (рисунок 1) $[4,9,13]$ :

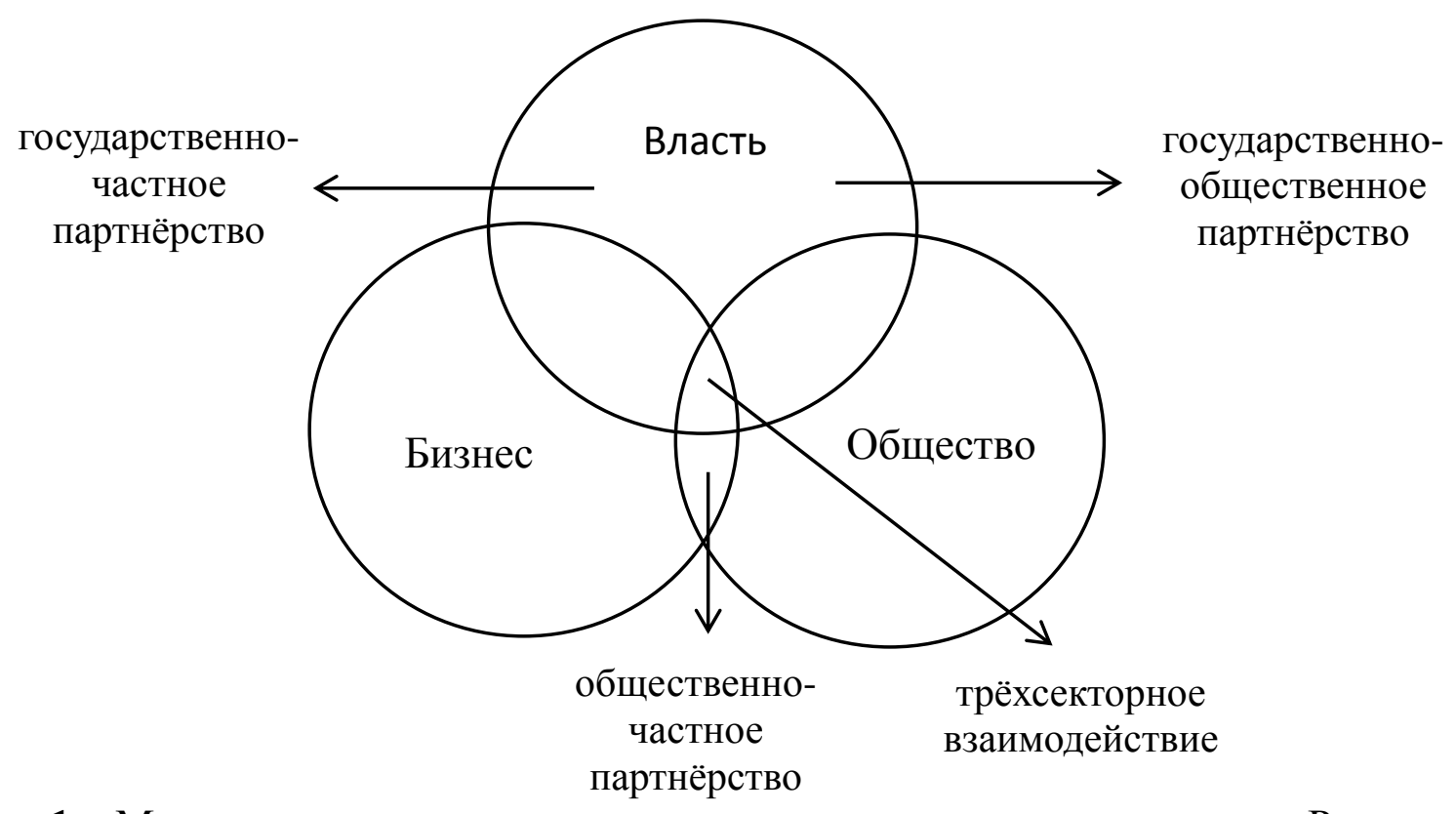

Рис. 1 - Модель реализации межсекторного социального партнерства в России

Согласно исследованиям Московского Центра Карнеги трёхсекторное взаимодействие сегодня в России не столь распространено в отличие от двухсекторных моделей. Существующую сегодня модель межсекторного социального партнёрства авторы изображают в виде треугольника, 
отражающего иерархию акторов в системе межсекторного взаимодействия (рисунок 2) [1].

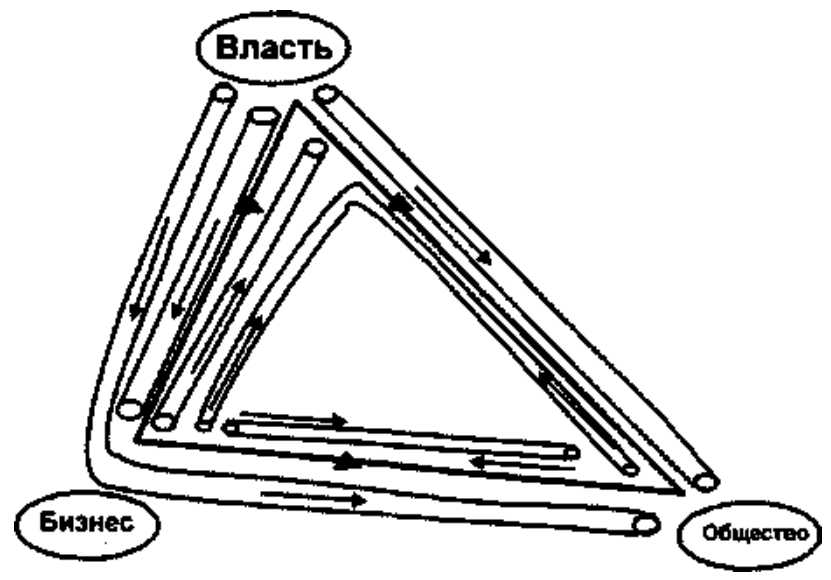

Рис. 2 - Модель взаимоотношений власти, бизнеса и общества в России

Данная модель иллюстрирует тот факт, что отношения между властью и бизнесом более тесные, чем, к примеру, между властью и обществом. Действительно, в последнее время большое развитие получили практики государственно-частного партнёрства.

В предлагаемой авторами модели власть занимает верхнюю вершину треугольника, в отличие от бизнеса и общества, что закрепляет за ней лидирующую позицию в системе партнёрства. На наш взгляд, власть действительно занимает ведущую роль в партнёрстве, выступая в качестве координатора процессов взаимодействия. В то же время положение бизнеса и общества также нельзя назвать пассивными.

Прямые и обратные связи между вершинами крайне асимметричны, что показано широкими трубами, по которым импульсы идут от власти к остальным акторам и гораздо более узкими трубками, ведущими от общества и бизнеса к власти, - движение хоть и двустороннее, но многополосное в сторону от власти и узкий проселок в сторону к власти (особенно от общества). Более того, некоторые связи в системе непрямые: часть импульсов от власти к обществу идет через бизнес, а от бизнеса к обществу - через власть.

Ряд исследователей рассматривают модели партнёрства в историческом аспекте, выделяя две модели межсекторного взаимодействия:

- патерналистская (российское государство с 1917 по 1990 гг.);

- партнёрская (с начала XX века) [3].

В патерналистской модели определяющим звеном, задающим принципы и условия в межсекторном взаимодействии и осуществляющим контроль за данным процессом, выступает власть, в то время как бизнес и некоммерческий сектор выступают в качестве со-партнёров.

Партнерская модель МСП предполагает большую степень горизонтальных связей между частниками партнёрства, что обусловлено 
достижением синергетического эффекта от объединения ресурсов каждого из партнёров.

Другие авторы [6] выделяют три модели межсекторного взаимодействия: англосаксонскую, китайскую и российскую.

Англосаксонская модель, наиболее яркими представителями которой являются США, Канада и Великобритания, характеризуются высокой степенью развитости всех трёх секторов, что обеспечивает её устойчивость и широкий спектр применения на практике социальных инноваций. Одной из главных отличительных особенностей США в сфере социальных инноваций и межсекторного взаимодействия является наличие развитой крупной системы благотворительности. Главная специфика китайской модели заключается в наличии сильного государства, которое определяет сферу деятельности коммерческих и общественных организаций. Российскую модель можно охарактеризовать как смешанную, так как она сочетает в себе наличие всех трех секторов каждый из которых обладает определенной автономией и самостоятельностью, с главенствующей ролью сильного государства.

Отдельные исследователи выделяют модели МСП исходя из трёх критериев:

- активности секторов (какое количество участвующих в партнёрстве секторов являются активными - один, два или все три);

- организованности (в зависимости от возникновения и управления процессом МСП: от стихийного и эпизодического до строго организованного);

- характера взаимодействия (имеется в виду роль каждого сектора в партнёрских отношениях: существует ли доминирующий актор или все участники равноправны).

Анализ существующих моделей межсекторного партнёрства показал, что исследователи выделяют модели межсекторного социального партнёрства согласно историческому, географическому и управленческому принципам. При этом все они отражают состав субъектов партнёрства и совокупность связей между ними как элементами системы. Структурный подход является классическим подходом к изучению предмета, который может быть использован при создании достаточно простых моделей.

Однако и при использовании данного подхода важно учитывать требования, предъявляемые к моделям. Анализ показал, что существующие модели МСП соответствуют трём требованиям, предъявляемым к моделям: согласованности со средой (ингерентность) [2], с субъектом, создающим и/или использующим модель (простота), с моделируемым объектом, то есть с создаваемой системой (адекватность) [8].

Однако реальный объект, подлежащий моделированию, требует не только структурного и статического, но и функционального, динамического моделирования.

Любая система существует и функционирует во времени. Состояния системы при этом сменяют друг друга. Именно поэтому важно оценивать 
качество функционирования системы. Сегодня такая оценка проводится с применением частных и общих критериев [11].

В настоящее время российскими учёными ведётся активная работа по созданию методического инструментария оценки уровня развития межсекторного социального партнёрства с применением количественных и качественных критериев. Существует ряд методик оценки МСП, позволяющих сравнивать территориальные образования по уровню партнерского взаимодействия государственного, коммерческого и некоммерческого секторов за разные промежутки времени. Однако единой методики оценки, полностью отвечающей современным условиям, к настоящему моменту не сложилось.

Помимо специальных методов моделирования межсекторного социального партнёрства, существуют методы моделирования при управлении коллективной и коалиционной деятельностью.

Академик Н.Н. Моисеев [7], рассматривая условия достижения согласия между субъектами, применил математические методы. В решаемой задаче нужно было создать такую систему отчислений на очистку воды, которая была бы выгодна предприятиям А и В. При этом в ходе исследований и расчётов учёный пришёл к выводу, что основой создания такой системы будет ситуация равновесия. Решение при этом должно быть: 1) выгодно всем участникам, а в случае невыполнения обязательств, ответственность должен нести нарушитель (устойчивый компромисс), эффективным (т.е. не улучшаемым сразу для всех партнёров). Однако на практике выполнение данных условий встречается нечасто, что приводит к затруднению развития теории коллективных решений

При моделировании коалиционной деятельности сегодня активно применяются методы теории игр, предметом которой является математический анализ конфликтных ситуаций, формализованное описание которых представлено в виде математической модели, определяющей некоторую игру. В коалиционных (кооперативных) играх, игроки могут принимать решения по согласованию друг с другом.

Для моделирования процессов коммуникации применительно к межсекторному партнёрству можно использовать взвешенный граф, в котором узлы следует разделить на группы, соответствующие различным секторам: бизнес, власть, общество. Веса при этом могут характеризовать свойства коммуникаций, например, стоимость коммуникации в зависимости от географической удаленности.

При управлении межсекторным социальным партнёрством могут использоваться и такие методы моделирования как когнитивные карты, сетевое моделирование, метод сценариев, модель принятия решений, известная как модель Карнеги и др.

Проведённое исследование позволило получить ряд результатов:

1) Межсекторное социальное партнерство является эффективным механизмом решения социально-экономических проблем. Однако для использования потенциала МСП необходимо его направленное развитие, мониторинг и устранение существующих проблем партнёрства. 
2) В управлении межсекторным социальным партнёрством целесообразно применять как специальные методы моделирования МСП, так и общие методы моделирования экономических систем, а также методы моделирования коллективной (коалиционной) деятельности. При выборе метода необходимо определить цель моделирования и критерий отбора отдельных элементов в создаваемую модель.

3) В современных исследованиях МСП большая часть внимания при моделировании уделяется структурному подходу, в то время как функциональному подходу отводится незначительная роль. Использование функционального подхода позволит не только построить модель реального объекта, но и на базе этой модели оценить показатели её функционирования и тем самым найти наиболее выгодный режим работы реальной системы МСП.

\section{Список литературы}

1. Власть, бизнес, общество в регионах: неправильный треугольник / под ред. Н. Петрова и А. Титкова; Моск. Центр Карнеги. М.: Российская политическая энциклопедия (РОССПЭН), 2010. 439 с.

2. Волкова В.Н., Денисов А.А. Основы теории систем и системного анализа. Изд. 2-е. - СПб.: СПб.ГТУ, 1999.

3. Грекова Г.И., Киварина М.В., Кузьмин А.В., Руденко К.А. Взаимодействие предпринимательских структур, власти и населения в системе социального партнерства / НовГУ имени Ярослава Мудрого. Великий Новгород, 2010. 242 с.

4. Копытова Е.Д. К вопросу о взаимодействии власти, бизнеса и общества в решении задач развития территорий // Экономические и социальные перемены: факты, тенденции, прогно3. 2017. Т. 10. № 5. C. 197-215. DOI: 10.15838/esc/2017.5.53.14

5. Межсекторное социальное партнерство. Развитие региональных моделей: монография/ Л.А. Осьмук [и др.]. Новосибирск: Новосибирский государственный технический университет, 2014. 168 с.

6. Михайлова А. Межсекторное взаимодействие как механизм создания социальных инноваций / А. Буравлева, А. Михайлова // Управление социальным развитием. 2017. №3. С.78-83.

7. Моисеев Н.Н. Экология человечества глазами математика: (Человек, природа и будущее цивилизации) / Н. Н. Моисеев. Москва: Молодая гвардия, 1988. $251 \mathrm{c}$.

8. Новиков А.М., Новиков Д.А. Методология научного исследования. М.: Либроком. 280 с.

9. Озина А. М., Чернышов А. М. Концептуальный аспект формирования механизма регулирования социально-экономических отношений в сфере услуг на основе социального партнерства // Вестник НГИЭИ. 2017. № 2 (69). С. 82-89. 
10. Оразбаев Б.Б., Курмангазиева Л.Т., Коданова Ш.К. Теория и методы системного анализа: учебное пособие. М.: Издательский дом Академии Естествознания, 2017. 248 с.

11. Приикер А. Введение в имитационное моделирование и язык СЛАМП М.: Мир, 1987. 229 с.

12. Советов Б.Я., Яковлев С.А. Моделирование систем. М.: Высшая школа, 1998.

13. Якимец В.Н. Межсекторное социальное партнерство (государство бизнес - некоммерческие организации). М.: ГУУ, 2002. 80 с. 